\title{
NASA World Wind: virtual globe for an open smart city
}

\author{
Maria Antonia Brovelli' ${ }^{1}$, Candan Eylül Kilsedar ${ }^{1}$, Patrick Hogan², Gabriele Prestifilippo ${ }^{1}$, \\ Giorgio Zamboni ${ }^{1}$ \\ ${ }^{1}$ Department of Civil and Environmental Engineering, Politecnico di Milano, Piazza Leonardo da Vinci 32, \\ 20133 Milan, Italy \\ ${ }^{2}$ NASA Ames Research Center, M/S 244-14, Moffett Field, CA USA \\ Corresponding author: \\ Candan Eylül Kilsedar ${ }^{1}$ \\ Email address: candaneylul.kilsedar@polimi.it
}

\begin{abstract}
In this article, firstly the open source framework NASA World Wind is introduced. NASA World Wind comes mainly with two versions. The Java version is well established in the market and has many customers. On the other hand the new version, which is the Web version, Web World Wind, is still at the dawn of development cycle, with many features implemented and already used in several applications, with a great future ahead. Following the introduction of NASA World Wind, the features available in the Web World Wind are listed and a short comparison with Cesium library is provided. Additionally, an application developed in the smart cities context with Web World Wind is described.
\end{abstract}

Keywords: NASA World Wind, Web, free and open source software, virtual globes, smart city, sustainability, data collection

\section{INTRODUCTION}

Considering the growth rate of world population and the shift of people from rural to urban areas, sustainability of cities must be addressed. In response to these challenges the concept of "smart city", where a collective approach to identify the needs of a city through the involvement of citizens has emerged. A suite of transformational IT tools, called "OpenCitySmart" is aimed to be used to increase the sustainability of urban life by supporting smart cities. In the network of "OpenCitySmart", technologies such as NASA World Wind Java, NASA World Wind Android, NASA Web World Wind, QGIS, GRASS GIS, PoliCrowd 2.0, iLocate and GeoMoose exist. The application presented here aims to select the technology that is most usable for citizens. The responsiveness and the ability to use the application with various devices is a 
key point to expand the usability. With this idea in mind, NASA Web World Wind, developed for JavaScript and HTML5 has been chosen.

\section{VIRTUAL GLOBES}

Virtual globes started expanding around 2004 with the open source version of NASA World Wind and later in 2005 with Google Earth. Being threedimensional they offered a more realistic way to represent the world compared to two-dimensional maps. Virtual globes provided many ways to visualize and interact with geographic data and other kinds of data. However, as Declan Butler said, "Google Earth and other virtual globes are set to go beyond representing the world, and start changing it." (D. Butler, 2006). This escalation is supported by applications in numerous areas, such as smart cities, disaster response, crowdsourcing, and more.

The virtual globes can be categorized into two groups: the first, running on desktop devices and the second, running on web browsers, evolved in the last few years, thus the modern ones. Regarding the modern virtual globes, the two most outstanding examples in open source domain are NASA Web World Wind and Cesium. These two leverage the latest technologies for Web: JavaScript, WebGL and HTML5. They can be used by non-experts thanks to their API (Application Programming Interface) and customized conveniently to meet the needs of case studies. This means that almost any computer programmer without advanced programming skills can create their own virtual globe application and share it with everyone via Web. Moreover, they can run on any device (desktop or mobile) and major operating systems, without having to install additional software, such as plugins or extensions. As a result, modern and open source virtual globe APIs increase the opportunity to create three-dimensional maps and to let users interact with them.

\section{NASA WORLD WIND}

NASA World Wind was created in 2003 and released under the NASA Open Source Agreement license in 2004. Right from the creation it became an important point of reference for the GIS (Geographic Information System) community and thanks to the features of the globe it spread fast among different fields. By the release of NASA World Wind, the approach to virtual globes changed as it expanded the user community who could interact with them. This mainly stemmed from the fact that differently from other virtual globes, NASA World Wind provided an SDK (Software Development Kit) based on Java programming language to customize the globe and create applications. Moreover, the virtual globe created using Java SDK can run on any operating system on desktop devices as long as the JVM (Java Virtual Machine) is installed. 
Following World Wind Java, Web World Wind has been released, based on Web technologies such as JavaScript, WebGL and HTML5. It can run on web browsers on any device and major operating systems, provided that WebGL is supported and enabled. It provides many features that any programmer can start using quickly following the examples on the reference website (https://webworldwind.org/). Among the features, there are graphical capabilities such as the display of placemarks, text, polygons, shapefiles, and imagery (JPEG, PNG and GeoTIFF) on the virtual globe. Besides the graphical capabilities some OGC standards are implemented such as WMS, WMTS, KML and Collada. Since it is an open source project, it is available on GitHub (https://github.com/NASAWorldWind/WebWorldWind/) and many programmers are involved in implementing new functionalities in the framework. Web World Wind can be customized without too much effort and extended easily by programmers. Thanks to this, many organizations are using it in several applications in the context of smart cities, urban planning, terrain visualizations and more.

\section{MODERN VIRTUAL GLOBES}

As stated before, two notable examples of modern virtual globes in open source domain are NASA Web World Wind and Cesium. Their APIs offer feasible ways to display and interact with a wide range of data. The differences between these two virtual globes are listed below:

1. Both frameworks are designed to display data via Web standards, but Web World Wind is focusing more on supporting formats used by the United States Department of Defense.

2. Web World Wind uses a geographic interface for configuring the objects in the virtual globe, while Cesium's primary interface is 3D-centric. Apart from the primary interface, a secondary interface using geographic coordinates is available.

3. Web World Wind supports different elevation data, such as WCS (Web Coverage Service) data and DTED (Digital Terrain Elevation Data). In the client, at run time, these are combined. Instead, Cesium supports proprietary elevation data, namely ESRI ArcGIS elevation data.

4. Web World Wind is designed to enable users to extend its functionalities by adding new components written in JavaScript and WebGL. On the other hand, Cesium is made of two interfaces, a high level one to interact with JavaScript and another one to interact with WebGL. 5. Cesium offers some functionalities, which are available only in the "Cesium Pro" version, which is a proprietary commercial version. Web World Wind offers all functionalities free of charge and does not have a "Pro" version. 


\section{WEB WORLD WIND SAMPLE APPLICATION}

The application developed with NASA Web World Wind aims to visualize data collected by citizens on a virtual globe. The architecture of the application can be seen in Figure 1. The data that is visualized on the virtual globe is collected using either ODK (OpenDataKit) platform or a cross-platform application called Via Regina, which are explained below. Both of the applications are developed within the framework of Via Regina project (http://www.viaregina.eu/), which is an INTERREG project (Cross-border Cooperation Operational Programme Italy - Switzerland, 2007 - 2013) realized thanks to the cooperation between universities, local administrations and cultural associations. The project aims at promoting, rediscovering and enhancing the naturalistic, artistic and cultural heritage along Via Regina, a cross-border area between Italy and Switzerland, on the West coast of Lake Como in the northernmost part of Italy (Antonovic et al., 2015).

ODK platform allows to collect POls (Points of Interest) through Android mobile devices and it is composed of three modules: ODK Build, ODK Aggregate and ODK Collect. ODK Build is used to design the survey form to set the questions to be asked. ODK Aggregate is used to provide blank forms to ODK Collect, store the content of the submitted forms and administer the users. ODK Collect is used to fill the blank forms and submit the filled forms to ODK Aggregate.

Via Regina is a cross-platform application developed using Cordova mobile application development framework. It is available as an application for Android and iOS operating systems and also on web browsers (http://viaregina3.como.polimi.it/app/). The map is built using mobile-friendly Leaflet library. Users are required to register and after registration they can insert a POI by answering some questions. The inserted POI is immediately available on the map as a marker and upon clicking the marker the answers given are shown inside a popup. In both applications the questions asked are stored in their database as the attributes of the POI and these attributes are decided in a way to fit the requirements of the Via Regina project. 


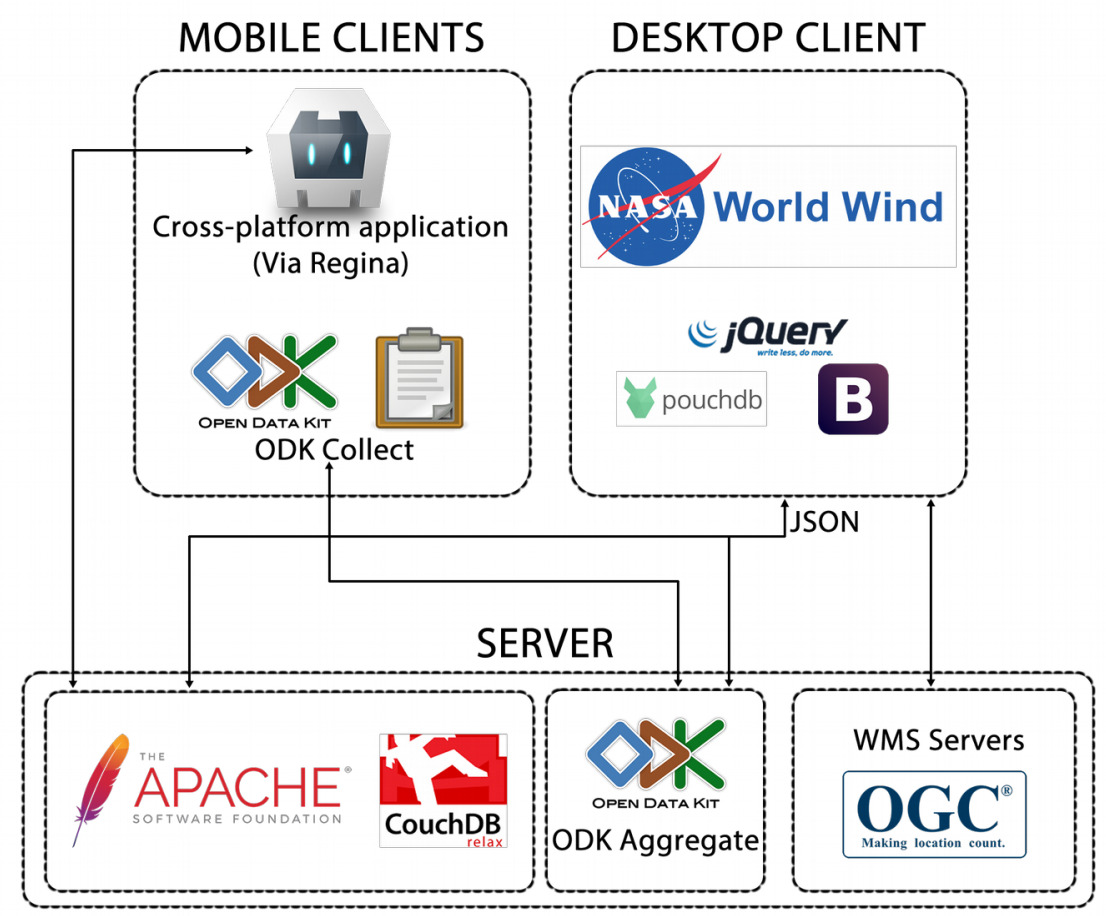

Figure 1. System architecture of the application

The application developed using the NASA Web World Wind API displays the POIs collected through the above mentioned two applications. For each POI, a marker is placed on the globe and upon clicking the marker the related data is shown inside a small window as visible in Figure 2. 


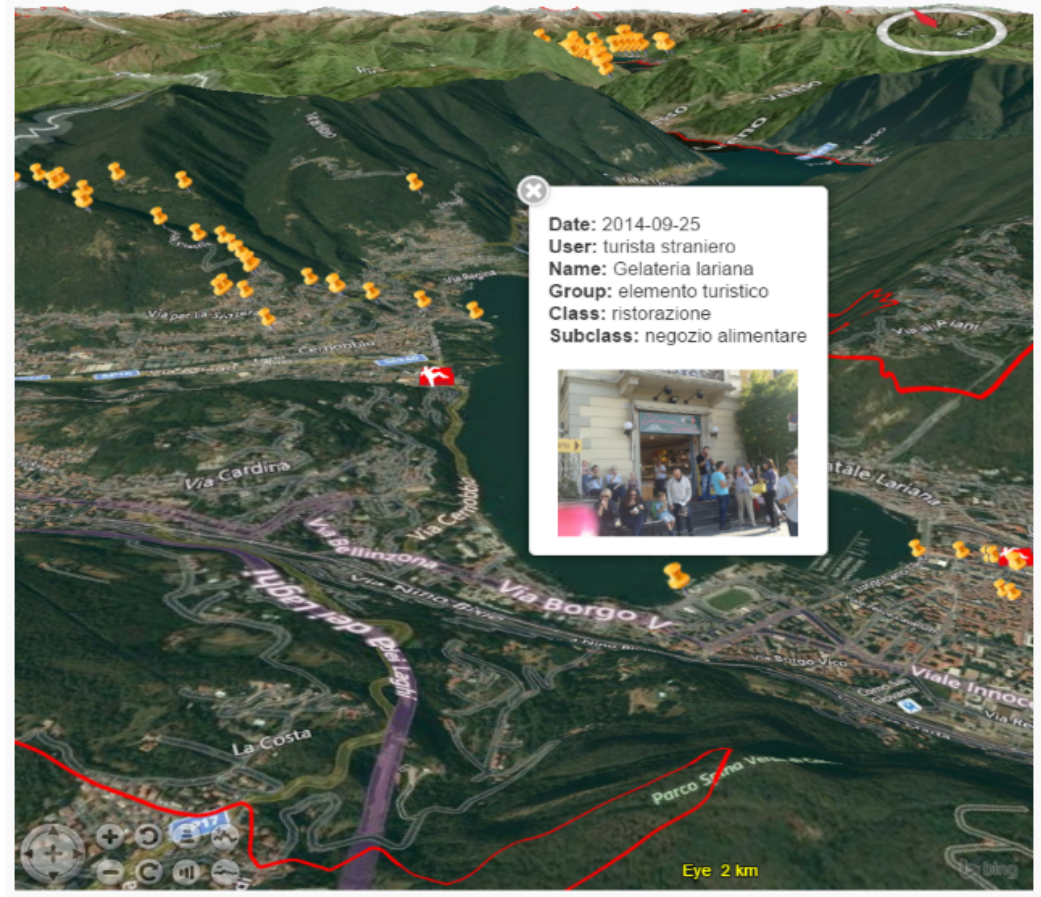

Figure 2. An example of queried data

The application can be used to let people report their ideas or issues related to the cities all around the world, and in this way involve citizens in the decision-making processes by informing authorities. The context of the application can be changed easily to fit different purposes modifying the two applications used to collect POls.

\section{CONCLUSIONS}

The capacity of a powerful framework, NASA Web World Wind, that can be used in many fields is demonstrated. It gives the programmers an opportunity to create numerous applications without too much effort. The framework, as previously mentioned, is still evolving, and the amount of applications using it in the last few years has grown rapidly, which notes that it has a great potential and it might become a point of reference in different fields, including smart cities.

Moreover, how computer technology can be used to empower citizens and foster the development of smart cities has been shown, through an application developed in the scope of OpenCitySmart. The application allows citizens to interact with the city and communicate information to responsible authorities as well to other citizens. The open source tool NASA Web World Wind has been chosen to develop the application as it is capable of running on desktop and mobile devices, on all major operating systems, without 
additional software installation.

\section{REFERENCES}

Antonovic M., Brovelli M. A., Cannata M., Cardoso M., Kilsedar C. E., Minghini M., Zamboni G. 2015. Promoting slow tourism through FOSS4G Web Mapping: an Italian-Swiss case study. Geomatics Workbooks $\mathrm{n}^{\circ} 12$ Proceedings of FOSS4G Europe Como 2015, pp. 99-104.

Brovelli M. A., Zamboni G. 2012. Virtual globes for 4D environmental analysis. Applied Geomatics, 4, pp. 163-172, ISSN: 1866-9298, DOI: 10.1007/s12518-012-0091-3.

Brovelli M. A., Minghini M., Zamboni G. 2013. Participatory GIS: Experimentations for a 3D Social Virtual Globe. International Archives of the Photogrammetry, Remote Sensing and Spatial Information Sciences, Volume XL-2/W2, pp. 13-18, DOI: 10.5194/isprsarchives-XL-2W2-13-2013.

Brovelli M. A., Hogan P., Minghini M., Zamboni G. 2013. The power of Virtual Globes for valorising cultural heritage and enabling sustainable tourism: NASA World Wind Applications. International Archives of the Photogrammetry, Remote Sensing and Spatial Information Sciences, Volume XL-4/W2, pp. 115-120, DOI: 10.5194/isprsarchives-XL-4W2-1152013.

Brovelli M. A., Minghini M., Zamboni G. 2014. Web-based Participatory GIS with data collection on the field: a prototype architecture. FOSS4G 2013 Academic Proceedings, Nottingham (UK), September 17-21, 2013, OSGeo Journal 13, pp. 29-33, ISSN 1994-1897.

Brovelli M. A., Minghini M., Zamboni G. 2014. Three Dimensional Volunteered Geographic Information: A Prototype of a Social Virtual Globe. International Journal of 3-D Information Modeling 3 (2), pp. 19-34, DOI: 10.4018/ij3dim.2014040102.

Brovelli M. A., Minghini M., Zamboni G. 2016. Participation in GIS via mobile applications. ISPRS Journal of Photogrammetry and Remote Sensing 114, pp. 306-315, DOI: 10.1016/j.isprsjprs.2015.04.002.

Brovelli M. A., Kilsedar C. E., Zamboni G. 2016. Visualization of VGI data through the new NASA Web World Wind virtual globe, ISPRS Journal of Photogrammetry and Remote Sensing, Volume XLI-B4, pp. 205-209, DOI: 10.5194/isprs-archives-XLI-B4-205-2016, 2016.

Butler D. 2006. Virtual globes: The web-wide world. Nature 439, pp. 776-778. 